Gestão e Desenvolvimento, 21 (2013), 147-172

\title{
SUPERVISÃO PEDAGÓGICA - UM ALICERCE PARA A CONSTRUÇÃO DO SABER
}

\section{Cheila Sá Pereira* Célia Ribeiro ${ }^{\dagger}$}

\begin{abstract}
Resumo: Para ensinar a ensinar é preciso aprender a ensinar $e$ também ao ensinar aprende-se. Todo este processo terá que ter como suporte a supervisão. A supervisão pedagógica, ao contrário do que se possa pensar, não está somente relacionada com a formação inicial dos futuros professores, mas também com a formação contínua, necessária para a evolução permanente de um profissional aprendente, que é o professor.

A formação deve ser feita num ambiente de ação-reflexão, envolvendo meios como a observação, o planeamento de atividades, a comunicação e a avaliação. Em todo o processo supervisivo, promove-se a aprendizagem $e$ o desenvolvimento humano $e$ profissional.

O objeto essencial da supervisão é a qualidade da formação e do ensino que se pratica ou praticará, não somente em contexto de sala de aula, mas abrangendo também a escola, como um desenvolvimento da qualidade organizacional e profissional dos que nela trabalham, através de uma aprendizagem que pode ser individual, mas num contexto coletivo.

Através de uma estrutura ou base, utilizando um determinado modelo, cenário, estilo ou abordagem, implementa-se a supervisão e esta deverá ser vista num contexto mais abrangente - a supervisão da escola e a supervisão da formação contínua.

A supervisão deverá constituir práticas críticas e autocríticas, existindo um compromisso ideológico de uma visão de educação e desenvolvimento profissional, como processos de transformação $e$
\end{abstract}

\footnotetext{
Mestre em Ciências da Educação pelo Departamento de Economia, Gestão e Ciências Sociais - Pólo de Viseu do Centro Regional das Beiras da Universidade Católica Portuguesa, tendo sido orientada pelo segundo autor

$\dagger$ Professora Auxiliar do Pólo de Viseu do Centro Regional das Beiras da Universidade Católica Portuguesa
} 


\title{
Cheila Sá Pereira e Célia Ribeiro
}

emancipação, ao nível institucional, cultural e social. Para se ser supervisor ter-se-á que ter uma visão do que é o ensino, orientando os formandos para a construção de uma sociedade democrática.

Palavras-chave: supervisão pedagógica; formadores; estagiários; professores; reflexão; escola.

\begin{abstract}
To teach how to teach it is necessary to learn to teach and also as we teach we learn. This whole process needs to be supported by supervision. The pedagogical supervision, contrary to what one might think, is not only related to the initial formation of future teachers, but also with the ongoing formation, necessary for the constant development of a professional learner, such as the teacher.

Formation should be done in an action-reflection environment, involving means such as observation, activities planning, communication and evaluation. Throughout the supervisory process, learning and human and professional development are promoted.

The essential object of supervision is the quality of the formation and of the education practiced or that will be practiced, not only in the classroom context, but also covering the school, as a development for organizational and professional quality of school collaborators, through a learning that can be individual, but in a collective context.

Through a structure or base, using a particular model, scenario, style or approach, supervision is implemented seeing this in a broader context - school supervision and ongoing formation supervision.

Supervision should constitute self-critical and critical practices, where there is an ideological commitment to a vision of education and professional development, as processes of transformation and emancipation, at the institutional, cultural and social level. To be a supervisor one has to have a vision of what teaching is, guiding the students to building a democratic society.
\end{abstract}

Keywords: pedagogical supervision, supervisors, trainees, teachers, reflection, school. 


\section{INTRODUÇÃO}

Durante muito tempo, a palavra supervisão, segundo Vieira (1993, p.28), esteve associada a conceitos como "chefia", "dirigismo", "imposição", "autoritarismo", mas esta conceção de supervisão está agora ultrapassada, abarcando uma perspetiva mais lata, tanto na formação inicial de professores como na formação contínua, devendo-se esta mudança às inúmeras investigações realizadas em Portugal.

A supervisão é um tema de máxima importância devido à necessidade de se encontrar a adequada formação para os professores no início das suas carreiras, pois o processo de formação e desenvolvimento dos professores estagiários repercute-se no desenvolvimento dos alunos e também porque "a verdadeira missão do professor consiste em ensinar a aprender, mas para ensinar a aprender é necessário aprender a ensinar” (Santos, 1977, p.183).

Segundo Alarcão e Roldão (2010, p.53), a supervisão é um "ambiente formativo estimulador" e tem como finalidade "apoiar e regular o desenvolvimento através de feedback, questionamento, apoio / encorajamento, sugestões / recomendações, sínteses / balanços, esclarecimentos conceptuais".

É necessário formar inicialmente homens e mulheres ricos em convicções e valores, de modo que a sua formação inicial seja um incentivo para que, futuramente, o seu trabalho profissional contribua para a construção de uma sociedade mais humana e realizada.

A temática da supervisão pedagógica deve ser vista como um alicerce para a construção do saber e conhecimento, bem como os vários modelos, cenários, estilos e abordagens da supervisão.

\section{SUPERVISÃO PEDAGÓGICA}

Ao longo do tempo, a supervisão configurou-se como um instrumento de formação e orientação, envolvendo formadores e alunos, com o intuito de promover o crescimento pessoal e profissional do formando, mas "ensinar os professores a ensinar deve ser o objectivo principal de toda a supervisão pedagógica" (Alarcão \& Tavares, 1987, p.34).

Concentrar-nos-emos na supervisão pedagógica, pois consideramos que esta é fulcral no processo de formação. 


\section{Cheila Sá Pereira e Célia Ribeiro}

\subsection{Conceitos de supervisão}

Muitas são as definições de supervisão, pois os conceitos têm evoluído ao longo dos tempos. Até aos anos 90, o termo era utilizado apenas em contexto de formação inicial. Segundo Alarcão e Tavares (1987, p. 18), a supervisão é "o processo em que um professor, em princípio mais experiente e mais informado, orienta um outro professor ou candidato a professor no seu desenvolvimento humano e profissional". Para Oliveira-Formosinho (2002, p.115), desta definição sobressaem "dois elementos fundamentais: a ênfase no processo e a ligação do desenvolvimento profissional ao desenvolvimento humano".

Vieira (1993) define supervisão como sendo "uma actuação de monitorização sistemática da prática pedagógica, sobretudo através de procedimentos de reflexão e de experimentação" (p.28). Sendo "um alicerce para a construção do conhecimento profissional" (Alarcão \& Roldão, 2008, p. 26), começa por questionarmos, analisarmos, interpretarmos, teorizarmos e essencialmente refletirmos, sempre com acompanhamento e permanente discussão dos resultados obtidos. Também Oliveira-Formosinho (2002, p.116) refere que da definição de Vieira "ressaltam dois outros elementos muito importantes (...) a reflexão e a experimentação".

Recentemente, a supervisão pedagógica já não está relacionada, somente, com a formação inicial, mas também com a formação contínua, onde o papel da supervisão assume também uma grande importância, quando equiparada à formação inicial. Já em 1987, Alarcão e Tavares referiam que "no quadro de formação contínua, a supervisão da prática pedagógica emerge como uma auto e heteroavaliação, comprometida e colaborante, em que os professores se entreajudam a desenvolver-se e a melhorar o seu próprio ensino" (p.148).

Das definições de supervisão apresentadas, sintetizam-se as seguintes conclusões, de acordo com Oliveira-Formosinho (2002):

- a supervisão é um processo de apoio à formação, seja ela inicial ou contínua;

- a formação deve ser vista como uma aprendizagem profissional contínua, que envolve pessoas, os seus saberes, as suas funções e as suas realizações;

- o caráter sistemático da formação deverá ser feito num ambiente de ação-reflexão das práticas na sala de aula;

- deverão ser usados meios para desenvolver o processo supervisivo, tais como a observação, a reflexão, o planeamento de atividades, o agir de novo, o diálogo, a comunicação, a avaliação; 
- todo o processo supervisivo, promove outros processos, tais como o processo de aprendizagem e desenvolvimento dos alunos, dos atuais e dos futuros.

(...) concebe-se a supervisão como apoio à formação, tendo da formação uma concepção integradora de várias dimensões: o currículo, o processo de ensino-aprendizagem, a sala de actividades e a escola, a sociedade e a cultura (...). A supervisão é, assim, um processo para promover processos. (...) Um processo complexo onde muito está previamente pensado, onde muito é emergente (Oliveira-Formosinho, 2002, pp.116-118).

Podemos então redefinir o conceito de supervisão e alargá-lo, tornando-o mais abrangente em todos os seus domínios. Assim, Alarcão e Tavares (2003) propõem um novo conceito de supervisão, sendo este um processo de "dinamização e acompanhamento do desenvolvimento qualitativo da organização escola e dos que nela realizam o seu trabalho de estudar, ensinar ou apoiar a função educativa, através de aprendizagens individuais e colectivas, incluindo a dos novos agentes" (p.154).

Esta redefinição de supervisão contempla, ainda mais, o desenvolvimento das capacidades dos futuros professores (estagiários) e o desenvolvimento profissional dos atuais professores, visto estar inserida num contexto mais abrangente, incidindo mais na supervisão da escola e na supervisão contínua.

Alarcão (2009) afirma que "mantendo como objecto essencial da actividade supervisiva a qualidade da formação e do ensino que praticam, a supervisão deve ser vista, não simplesmente no contexto da sala de aula, mas num contexto mais abrangente da escola, como um lugar e um tempo de aprendizagem para todos" (p.120).

Citados por Alarcão (2009, p. 120), Sullivan e Glantz, em 2000, afirmavam que a supervisão do século XXI teria fundamentalmente duas características: "a democraticidade e a liderança com visão". Democraticidade, porque todo o trabalho de supervisão seria baseado em trabalho colaborativo entre os professores, havendo partilha e práticas reflexivas, decisões participadas, em suma, havendo mais e melhor autonomia entre os pares. Liderança com visão, de modo a haver uma perspetiva do futuro, promovendo os valores da democraticidade e desenvolvendo "programas supervisivos com impacto" (Alarcão, 2009, p.120).

Em suma, da definição proposta por Alarcão e Tavares, em 1987, já citada, onde um professor mais experiente orientava o trabalhado de outro professor ou de um futuro professor, passámos a considerar a supervisão 
"num contexto mais abrangente, que é a supervisão da escola e a supervisão da formação contínua, ou seja, do colectivo dos docentes" (Alarcão, 2009, p. 120), ficando a supervisão mais associada ao desenvolvimento profissional, não só dos futuros professores, mas também dos que já se encontram em ambiente de formação contínua.

A supervisão passou a ser um "processo de desafios, acompanhados de apoio para que as pessoas sejam capazes de responder aos desafios (...) mantidos ao longo da história" (Alarcão, 2009, p.121).

A formação de professores é essencial e pode ser vista como um vetor que nos leva a "bom porto" com as reformas e orientações normativas, mostrando-se condição necessária para que ocorram mudanças e exista inovação, garantindo melhor qualidade de qualificação dos docentes, logo, melhor qualidade de ensino e melhores resultados de aprendizagem.

"Os supervisores do ensino terão que ir ao baile e conduzir a dança" (Harris, 2002, p. 197), mas de que maneira?

\section{MODELOS DE SUPERVISÃO}

Para compreendermos melhor a noção de supervisão, torna-se necessário estudar os vários modelos de supervisão, para encontrar em cada um deles aspetos importantes e uma mais valia para a ação supervisiva.

Ao longo dos anos foram surgindo vários modelos. Uns privilegiam a aprendizagem das crianças; outros focam-se mais no papel do professor/educador; uns apoiam-se mais no produto final, enquanto outros valorizam somente o percurso. Alguns salientam que o importante é a relação com o contexto da prática; outros invocam o papel do supervisor, como um construtor do conhecimento ou dão mais importância ao percurso reflexivo dos professores (Tracy, 2002).

Mas afinal, o que são modelos? No Second Handbook of Researche on Teaching (Nuthal \& Snook, 1973, citados por Tracy, 2002, p. 21) afirma-se que o termo modelo é muitas vezes usado e intercalado com termos "como abordagem, teoria ou paradigma". Modelo, num contexto supervisivo pode ser uma abordagem, um paradigma, um padrão, ou não. Tracy $(2002$, p. 22) propõe que o termo modelo seja "frequentemente definido em relação ao desenvolvimento da investigação". Modelo deve ser uma estrutura ou uma base, composto por procedimentos, de forma a poder-se implementar a supervisão pedagógica dirigida a professores e candidatos a professores.

Sergiovanni e Starratt (1993), citados por Tracy (2002, p.27), utilizam a metáfora das janelas e dos muros, para indicarem benefícios e não 
benefícios aos modelos de supervisão, afirmando que, num contexto supervisivo, "os modelos criam também janelas múltiplas pelas quais podemos ver o mundo da prática".

Como janelas ajudam a expandir a visão das coisas, a solucionar problemas e a fornecer respostas, dando-nos as bases necessárias para funcionarmos como investigadores e profissionais da prática. Como muros, estes mesmos modelos servem para nos limitar, para nos obstruir a visão de outras concepções da realidade, de outras percepções e de outras alternativas (Tracy, 2002, p. 26).

Um modelo pode permitir ver melhor a forma como se deve implementar a supervisão pedagógica, mas também pode ser um obstáculo, caso não seja utilizado convenientemente e se não tivermos noção de todos os fatores que rodeiam a organização escolar. Também devemos ter em conta os aspetos onde nos identificamos com os mesmos.

Apoiados em Tracy (2002), que pesquisou e escreveu sobre os vários modelos e suas abordagens, salientamos alguns aspetos mais significativos de cada modelo, tendo presente que o objetivo dos modelos de supervisão, "é o de responder aos interesses do professor - o crescimento e desenvolvimento individual (...) acompanhada (...) na obtenção dos objectivos escolares" (Tracy, 2002, p. 33).

Tracy (2002) apresenta-nos seis trabalhos, classificando, em cada um deles, os modelos de supervisão pedagógica (ASCD, 1982; Glatthorn, 1984; McGreal, 1983; Pajak, 1993; Sergiovanni e Starratt, 1993; Tracy e MacNaugthon, 1993).

Em primeiro lugar, refere que no Anuário de 1982 da Association of Supervision and Curriculum Development (ASCD) encontramos três modelos ou abordagens da supervisão: o modelo científico, baseado em McNeil (1982); o modelo clínico, baseado em Garman (1982), Cogan (1982) e Goldhammer (1982); o modelo artístico, baseado em Eisner (1982).

No modelo científico, a supervisão pedagógica é usada para se verificar o nível e a qualidade do ensino apresentados. No segundo modelo, o modelo clínico, realça-se as interações colaborativas entre o professor e o supervisor, onde nenhum deles pode desenvolver ou interpretar completamente o significado dos acontecimentos, sozinho, valorizando-se a confiança e a utilidade. A terceira abordagem, a artística, foca-se nos potenciais do estilo único do professor e tenta-se auxiliá-lo na exploração desses mesmos potenciais. O objetivo principal do supervisor é o de assistir o professor com o intuito de fortalecer os valores que exemplifiquem uma educação de qualidade. 
Glatthorn (1984), citado por Tracy (2002, p.44), apresenta quatro modelos de supervisão que surgem como uma série de quatro opções disponíveis para os supervisores, podendo ser misturadas e/ou combinadas entre si: o modelo de supervisão clínica, baseado em Cogan (1973) e Goldhammer (1969), Hunter (1984, 1990), McNeil (1971) e Eisner (1982); o modelo do desenvolvimento profissional cooperativo; o modelo do desenvolvimento autodirecionado, baseado em Iwanicki (1981) e Redfern (1980); e, por último, o modelo da monitorização administrativa.

No modelo de supervisão clínica de Glatthorn (1984), a supervisão clínica é centrada na aprendizagem. O principal objetivo deste modelo é "assistir, e não avaliar, o professor" (Tracy, 2002, p. 44) apesar do supervisor manter o controlo de todo o processo supervisivo. Segundo Glatthorn (1984), citado por Tracy (2002, p.44), o público-alvo para este tipo de supervisão, são os "professores inexperientes"ou os "professores experientes", mas que querem alterar radicalmente a sua maneira de trabalhar.

O modelo de desenvolvimento profissional cooperativo é, por vezes, designado de "supervisão colegial ou de pares" (Tracy, 2002, p.45). Glatthorn (1984) apresenta aqui um pequeno desvio da noção de supervisão, pois neste modelo, "dois ou mais professores trabalham conjuntamente para o seu próprio desenvolvimento profissional", havendo "um número mínimo de observações das turmas do(s) respectivo(s) colega(s), feedback e a discussão de outros interesses profissionais partilhados" (Tracy, 2002, p.45). Uma vez mais, o objetivo deste modelo não é avaliar, mas sim encorajar.

O modelo de desenvolvimento autodirecionado é referido por McGreal (1983), e por Tracy e MacNeughton (1993), "como um modelo de estabelecimento de objectivos ou de objectivos de realização" (Tracy, 2002, p. 45). Neste modelo, cabe essencialmente ao professor, embora monitorizado pelo supervisor, controlar o processo, sendo, outra vez, não avaliativo. Um dos aspetos negativos deste modelo é o professor trabalhar independentemente, em vez de supervisionado. É mais um modelo de supervisão autónoma e independente.

O modelo de monitorização administrativa é o único modelo de Glatthorn (1984) que pode ser usado tanto para supervisionar e acompanhar o trabalho do professor, como para o avaliar.

Já McGreal (1983), citado por Tracy (2002, p. 47), apresenta cinco classificações de modelos, que variam entre a avaliação, a assistência e os resultados estabelecidos: o modelo de normas comuns; o modelo de estabelecimento de objetivos, baseado em Iwanicki (1981); o modelo de 
produto, baseado em Popham (1973) e McNeil (1971); o modelo de supervisão clínica, baseado em Cogan (1973), Goldhammer (1969), Acheson e Gall (1980), Boyan e Copeland (1978); o modelo artístico ou naturalista, baseado em Eisner (1982, 1983) e Sergiovanni (1982).

O modelo de normas comuns é o modelo usado frequentemente para avaliação das práticas de supervisão nas escolas. Este modelo tem uma propensão para a avaliação. $\mathrm{O}$ supervisor detém quase exclusivamente $\mathrm{o}$ controlo, observa as aulas e avalia, sendo o professor um participante relativamente passivo.

O modelo de estabelecimento de objetivos é análogo ao modelo de Glatthorn (1984), citado anteriormente, mas difere nos objetivos. Este modelo situa-se numa linha de assistência ao professor.

O modelo de produto centra-se em resultados especificados e baseiase em medidas de desempenho dos alunos ao nível do comportamento, desenvolvimento de competências, conhecimento da matéria e atitudes, para descrever a eficácia do ensino, em vez de se basear no processo de ensino.

O modelo de supervisão clínica centra-se no processo de ensino, mais do que nos seus resultados; roga a assistência e nega a avaliação do desempenho do professor. Logo, este modelo não se adequa para a avaliação.

O modelo artístico ou naturalista tem como pilar os resultados obtidos através de uma supervisão construída mais a partir da teoria do que da prática, de modo a ajudar os professores na tarefa de desenvolverem os seus próprios talentos.

Pajak (1993), citado também por Tracy (2002, p. 50), propõe quatro modelos clínicos de supervisão pedagógica, que podem ser classificados de modelos de "supervisão clínica" a enunciar: o modelo original, baseado em Goldhmmer (1969), Mosher e de Purpel (1972) e Cogan (1973); o modelo humanístico-artístico, baseado em Blumberg (1974, 1980) e Eisner (1982, 1983); o modelo técnico-didático racional, baseado em Acheson e Gall (1980, 1987, 1992), Hunter (1979), Joyce e Showers (1980, 1982, 1988); o modelo desenvolvimental/ reflexivo, baseado em Glickman (1980, 1981, 1987, 1990), Garman (1982, 1986), Schön (1983, 1988), Costa e Garmston (1985, 1994), Zeichner e Liston (1987), Bowers e Flinders (1991) e Retallick (1986).

O modelo original é o modelo de supervisão clínica de Goldhammer (1969), Mosher e de Purpel (1972) e Cogan (1973). Tem por grande objetivo prestar assistência e apoio ao professor, de modo a que este, gradualmente, seja capaz de se auto-supervisionar. 
O modelo humanístico-artístico de Pajak (1993), inclui o modelo de intervenção interpessoal de Blumberg (1974, 1980), que aposta nas relações humanas entre os diversos intervenientes envolvidos no processo de aprendizagem e o modelo de Eisner (1982, 1983), já referido anteriormente, onde "o ensino é conceptualmente visto mais como arte do que como ciência (...) é a transformação do currículo em acção" (Tracy, 2002, p. 52).

O modelo técnico-didático racional, contrasta com o anterior, na medida em que o conhecimento é detido e controlado por especialistas, onde o professor é um consumidor desse tal conhecimento.

O modelo desenvolvimental/ reflexivo inclui a supervisão desenvolvimental de Glickman (1980, 1981, 1987, 1990), o modelo de treino cognitivo de Costa e Garmston $(1985,1994)$, a visão da prática reflexiva de Schön (1983, 1988), Zeichner e Liston (1987), entre outros, onde a conceção da prática profissional tem por base a capacidade do professor para aprender a partir da experiência e refletir criticamente sobre as suas próprias ações.

Sergiovanni e Starratt (1993) apontam cinco opções à volta das quais a supervisão escolar se pode organizar, onde os professores devem desempenhar papéis-chave nas tomadas de decisão relativas às opções que mais se adaptam às suas necessidades, num determinado momento. Tanto os professores como os supervisores desempenham vários papéis, tendo como tema organizador a "autoridade profissional (...) definida como conhecimento informado da profissão e conhecimento pessoal" (Sergiovanni \& Starratt, 1993, citados por Tracy, 2002, p. 58), isto é, reconhecimento de que a melhor forma de efetuar a supervisão é através do conhecimento profissional da prática e esta deve estar desligada dos papéis hierárquicos da organização, prevalecendo um bom clima de diálogo e apoio. As cinco opções são: supervisão clínica, baseada em Cogan (1973) e Goldhammer (1969); supervisão colegial; supervisão autodirecionada; supervisão informal; supervisão baseada na pesquisa.

Na supervisão clínica, todo o processo supervisivo inclui reuniões, observação de professores na sua prática e análise de resultados, sendo uma relação colegial entre o supervisor e o professor, tendo ambos responsabilidades, mas onde o professor é "quem decide o enfoque da supervisão e os assuntos a serem discutidos" (Tracy, 2002, p. 59).

A supervisão colegial é análoga ao modelo já enunciado de Glatthorn (1984) - desenvolvimento profissional cooperativo. O trabalho dos professores pode ser em grupo de dois ou três, não se baseando só no contexto de sala de aula, mas também inclui reuniões, discussões e 
partilha na preparação de aulas. $\mathrm{O}$ supervisor tem a responsabilidade final, mas o professor tem voz ativa na tomada de decisões.

A supervisão autodirecionada, também é semelhante ao modelo de Glatthorn (1984), já citado. Os professores ao trabalharem sozinhos assumem responsabilidades pelo seu trabalho.

A supervisão informal decorre de uma série de encontros informais ou casuais entre o supervisor e o professor, onde o supervisor pode observar aulas sem marcação prévia. Aqui, os supervisores têm a responsabilidade de todo o processo de ensino de uma escola.

A supervisão baseada na pesquisa, pode ser realizada entre o supervisor e o professor "onde este é um observador da sua própria instrução" (Tracy, 2002, p.61).

Tracy e MacNaughton (1993) apresentam três modelos: o modelo orientado para meios, sendo um o tradicional e o outro o neotradicional, baseado em Hunter (1984, 1987) e Minton (1979); o modelo orientado para objetivos, tendo estes objetivos educacionais, baseado em McNeil (1971), e objetivos de desempenho, baseado em Redfern e Iwanicki (1984); o modelo orientado para o professor, baseado em Cogan (1973), Goldhammer (1969), Boyan e Copeland (1978).

No modelo orientado para meios, o foco da supervisão recai sobre as estratégias utilizadas pelo professor para obter os resultados educacionais desejados, considerando que há uma relação de causa e efeito entre as estratégias delineadas para o ensino e a aprendizagem do aluno.

No modelo orientado para objetivos, a abordagem de objetivos educacionais é um desenvolvimento do modelo científico de McNeil (1982), já citado no anuário da ASCD, onde o vetor orientador é o de auxiliar o professor a projetar a sua instrução, de modo a que os alunos atinjam os objetivos educacionais. Este modelo envolve "quatro passoschave: 1) reunião de pré-observação; 2) observação; 3) análise e estratégia; 4) reunião de pós-observação. Estes passos são paralelos aos da supervisão clínica" (Tracy, 2002, p.63). Como a educação atual vive de resultados, este modelo tem propensão futura.

O modelo orientado para o professor, contrariamente aos dois anteriores, não está pré-estabelecido, e o foco da supervisão é decidido pelo professor e não pelo supervisor ou por critérios externos.

Tracy (2002) afirma que o modelo da supervisão clínica pode ser encarado como um modelo distinto dos demais, como sendo mais uma abordagem para uma supervisão eficaz, do que um modelo isolado e único. 
$\mathrm{Na}$ maioria dos modelos descritos, o papel do professor e do supervisor não varia muito, tendo ambos responsabilidades nas suas funções. Consideramos que não devemos optar por um único modelo em detrimento dos outros, pois alguns completam-se entre si. Importa ainda salientar que os modelos de supervisão baseiam-se nos seguintes objetivos, segundo Tracy (2002, p. 80):

1. O professor é o protagonista no processo de transmissão de ensino; 2 . O ensino é um acto observável; 3. O acto de ensinar ocorre num tempo e lugar predeterminados nos quais o supervisor pode estar presente; 4. Os comportamentos de ensino do professor e as interacções com os alunos são acontecimentos significativos a observar no ambiente de aprendizagem; 5. A interacção professor-supervisor é um meio eficaz de identificação dos aperfeiçoamentos pedagógicos necessários; 6. A interacção professorsupervisor deveria ocorrer face a face.

Os objetivos da supervisão do futuro deverão incidir mais na aprendizagem e não tanto no ensino, devendo centrar-se na colaboração e no desempenho do trabalho de grupo, fornecendo paralelamente feedbacks suficientemente pormenorizados para se tornar útil o aperfeiçoamento individual do professor.

A futura geração de modelos de supervisão deverá incluir os seguintes pressupostos, segundo Tracy (2002, p.83):

1. A escola é uma comunidade constituída por elementos que são aprendizes ao longo de todo o seu ciclo de vida; 2 . As pessoas são capazes de assumir responsabilidade pelo seu desenvolvimento, de se autodirigirem e de se auto-supervisionarem, quando têm acesso a recursos e mecanismos de acompanhamento adequados; 3 . Os aprendizes adultos têm as suas necessidades próprias, distintas das necessidades das crianças; 4. Para melhorar o desempenho de qualquer indivíduo, devemos ter em consideração o ambiente organizacional global no qual as pessoas trabalham; 5. As pessoas aprendem melhor e são motivadas pela colaboração com os outros.

Não podemos terminar com a apresentação dos modelos de supervisão pedagógica, sem antes nos referirmos ao modelo usado por OliveiraFormosinho (2002), o modelo ecológico de supervisão pedagógica, baseado numa relação tripartida, entre o/a estagiário/a, o/a educador/a cooperante e o/a docente da instituição de ensino superior. Este modelo é inspirado em Bronfenbrenner (1979), no ambiente ecológico por ele descrito e respetivas "estruturas concêntricas" (Oliveira-Formosinho, 2002, p. 100). 
O desenvolvimento de qualquer ser humano tem a ver, direta ou indiretamente, com o contexto onde está inserido. Devemos refletir sobre a importância de perceber cada aluno no seu respetivo contexto de aprendizagem. É proposta uma comparação deste modelo ecológico à imagem das matrioscas russas, onde cada conjunto é intercalado com o anterior, formando um todo no final.

O modelo ecológico para a supervisão constrói-se, segundo OliveiraFormosinho (2002, pp.101-102), com base em três pontos de partida: o reconhecimento da importância da instituição de formação, ou seja, da universidade, da escola onde exercem o estágio e da sala de estágio; o reconhecimento da importância das interações ocorridas nos espaços anteriormente citados e o reconhecimento da importância das influências sociais e culturais ocorridas durante o estágio. É necessário que o supervisor desenvolva capacidades supervisivas que o ajudem a observar os procedimentos dos alunos e a interpretá-los, de forma a torná-los conscientes das situações e a conseguir questionar a sua prática, relacionando-a com a teoria aprendida.

Os modelos de supervisão completam-se, na medida em que cada um valoriza aspetos significativos da prática supervisiva, que em conjunto demonstram a complexidade e exigência desta tarefa.

\section{CENÁRIOS DE SUPERVISÃo}

Não podíamos deixar de apresentar os cenários de supervisão de Alarcão e Tavares (2003), não esquecendo que não existe obrigatoriedade em utilizar um em detrimento de outro. São coexistentes, completam-se, tendo em conta a prática supervisiva e os contextos culturais necessários. Passamos a descrever, resumidamente os nove cenários propostos e apresentados pelos autores supracitados:

- Cenário da imitação artesanal: aqui está presente a ideia de imitar o mestre, onde os futuros professores aprendem praticando com o "experiente", sendo "moldados pelo artesão e a ser, através dele, socializados" (Alarcão \& Tavares, 2003, p.17). Não consideramos que seja um modelo muito eficaz, pois a imitação não é a melhor maneira de aprender.

- Cenário da aprendizagem pela descoberta guiada: põe em ênfase a capacidade de descoberta, de imaginação e de autocrítica, analisando os resultados em diferentes situações, onde o futuro professor deverá conhecer os modelos teóricos, observar diferentes professores em atuação e experimentá-los, sendo um processo progressivo, onde se parte de uma componente teórica passando para uma componente prática. 
- Cenário behaviorista: onde é utilizada a estratégia do microensino, utilizada nos anos 60. Este cenário assenta na ideia de que todos os professores executam determinadas tarefas, sendo depois analisadas e explicadas aos futuros professores, que, mais tarde, as irão experimentar numa aula específica para o efeito. Neste cenário são antecipadas situações reais. Peca, pois em situação de contexto de sala de aula, por vezes, surgem situações para as quais os futuros professores não foram preparados, pois não podemos prever como o aluno reage às tarefas propostas.

- Cenário clínico: tem como principal objetivo melhorar a prática de ensino dos futuros professores, tendo eles um papel ativo. É solicitada a colaboração do supervisor no processo de observação, responsabilidade, análise, reflexão e avaliação, "com vista ao aperfeiçoamento da prática docente com base na observação e análise das situações reais de ensino" (Alarcão \& Tavares, 2003, p.26).

- Cenário psicopedagógico: tem como objetivo ensinar a ensinar. O papel do supervisor é desenvolver capacidades e competências nos futuros professores, ensinando-lhes a explorar os conhecimentos que dispõem, de modo a resolverem os problemas que lhes aparecem, transferindo as mesmas capacidades para os alunos. Consideramos importante a relação próxima que é criada entre o supervisor e o aluno/formando.

- Cenário pessoalista: visa o desenvolvimento da pessoa do professor, o aspeto humanista, através da reflexão a que os formandos são incentivados a fazer, após a prática pedagógica, e também o aumento do autoconhecimento e da autoconfiança, para a construção de um futuro professor mais humano.

- Cenário reflexivo: defendido por Schön (1983, 1987), citado por Alarcão e Tavares, (2003) e já citado nos modelos apresentados por Tracy (2002), foi o grande impulsionador deste tipo de supervisão. Este cenário baseia-se no trabalho prático em situação real que serão, constantemente, objeto de análises reflexivas, onde o formando progride no seu desenvolvimento, construindo a sua forma pessoal, o seu "eu", orientando-se para um caminho que o levará ao bom profissional de ensino.

- Cenário ecológico: da autoria de Bronfenbrenner (1979), já citado e adaptado por Oliveira-Formosinho (2002), este cenário tem em consideração as dinâmicas sociais e as dinâmicas sinergéticas que se estabelecem na "interacção que se cria entre a pessoa, em desenvolvimento, e o meio que a envolve, também ele em permanente transformação" (Alarcão \& Tavares, 2003, p.37). 
- Cenário dialógico: onde os professores são vistos como atores sociais. A supervisão é colaborativa e não individualizada. O supervisor observa e ouve o formando, numa abordagem dialogante, onde a supervisão é "baseada em relações simétricas de colaboração e de base clínica" e deve funcionar "como instrumento de emancipação individual e colectiva dos professores" (Alarcão \& Tavares, 2003, p.41).

Alarcão e Tavares (2003) propõem ainda três ideais fundamentais, que deverão presidir à supervisão pedagógica de professores:

1. O professor é uma pessoa, um adulto, um ser ainda em desenvolvimento, com um futuro de possibilidades e um passado de experiências; 2. O professor, ao aprender a ensinar, encontra-se ele próprio numa situação de aprendizagem; 3. O supervisor é também uma pessoa, também ele um adulto em desenvolvimento, geralmente com mais experiência; a sua missão consiste em ajudar o professor a aprender e a desenvolver-se para, através dele, influenciar a aprendizagem e o desenvolvimento dos alunos (Alarcão \& Tavares, 2003, p.42).

Mas como atua o supervisor?

\title{
4. ESTILOS E ABORDAGENS DE SUPERVISÃO
}

A principal atuação do supervisor é ajudar.

\begin{abstract}
A supervisão deve configurar-se como um processo humanista e desenvolvimentista, de natureza essencialmente relacional, cuja essência se traduz no estabelecimento de relações facilitadoras do desenvolvimento dos futuros educadores/professores, baseadas em atitudes de ajuda, disponibilidade, autenticidade, encorajamento e empatia dos supervisores, as quais se constituem, afinal, como factores de promoção do crescimento e da aprendizagem dos formandos (Gonçalves, 2009, p.29).
\end{abstract}

Os estilos de supervisão deverão ser vistos como a forma de atuação do supervisor, no seu processo supervisivo. Glickman (1985), citado por Gonçalves (2009), propõe três pré-requisitos que devem estar presentes na ação do supervisor: o conhecimento, as competências interpessoais ou skills interpessoais e as competências técnicas, que no seu todo dão corpo aos estilos de supervisão. Para Glickman (1985), citado por Alarcão e Tavares (2003, p.74), os skills interpessoais são identificados em dez categorias: "1) prestar atenção; 2) clarificar; 3) encorajar; 4) servir de espelho; 5) dar opinião; 6) ajudar a encontrar soluções para os problemas; 7) negociar; 8) orientar; 9) estabelecer critérios; 10) condicionar". O mesmo autor afirma que a ênfase dada a um ou outro skill é que irá determinar o estilo supervisivo adotado. 
Glickman (1985), citado por Alarcão e Tavares (2003), propõe três tipos de estilos de supervisão:

- Não-diretivo, onde o supervisor procura entender o mundo do professor que acompanha. O supervisor deixa o formando tomar iniciativas, verbalizar as suas opiniões e ajuda-o a compreender e clarificar as suas ideias, encorajando-o e incentivando-o na aplicação de novas estratégias, ajudando a encontrar o seu caminho e a personalizar o seu ensino.

- De colaboração, onde o supervisor utiliza estratégias de colaboração, expressando frequentemente a sua opinião relativamente ao trabalho executado pelo formando, fazendo uma leitura e análise pessoal, dando sugestões, verbalizando, fazendo sínteses das sugestões e dos problemas apresentados, ajudando a resolvê-los.

- Diretivo, onde o supervisor dá orientações e estabelece critérios e normas e condiciona as atitudes do formando.

Mais uma vez, e agora relativamente aos estilos de supervisão, eles não devem ser vistos separadamente, mas poderão completar-se e aparecerem num contínuo enquadramento, conforme nos é sugerido pelo quadro seguinte: 


\section{Quadro I}

Estilos de supervisão, segundo Glickman (1985)

\begin{tabular}{c|c|c|c|c}
\hline Estilos de & $\begin{array}{c}\text { Prestar } \\
\text { atenção; } \\
\text { clarificar; } \\
\text { encorajar }\end{array}$ & $\begin{array}{c}\text { Servir de } \\
\text { espelho }\end{array}$ & $\begin{array}{c}\text { Dar opinião; } \\
\text { ajudar a } \\
\text { encontrar } \\
\text { soluções; } \\
\text { negociar }\end{array}$ & $\begin{array}{c}\text { Orientar; } \\
\text { estabelecer } \\
\text { critérios; } \\
\text { condicionar }\end{array}$ \\
\hline Não-directivo & & & & \\
\hline De colaboração & & & & \\
\hline Diretivo & & & & \\
\hline
\end{tabular}

Fonte: adaptado de Alarcão e Tavares (2003, p. 76).

Severino (2007), citado por Gonçalves (2009), propõe também três estilos de supervisão, de acordo com o quadro II:

\section{Quadro II}

Estilos de supervisão, segundo Severino (2007)

\begin{tabular}{c|c|c|c}
\hline $\begin{array}{c}\text { Estilos de actuação } \\
\text { do supervisor }\end{array}$ & $\begin{array}{c}\text { Tipo de supervisão } \\
\text { praticada }\end{array}$ & O que valoriza & Tipos de supervisão \\
\hline Prescritivo & Supervisão activa & $\begin{array}{c}\text { Os comportamentos a } \\
\text { desenvolver }\end{array}$ & $\begin{array}{c}\text { - académico, mestre, } \\
\text { mentor, crítico }\end{array}$ \\
\hline Interpretativo & Supervisão activa & As ideias & $\begin{array}{c}\text { - humanista, } \\
\text { reformulador }\end{array}$ \\
\hline Apoiante & Supervisão reactiva & A pessoa & $\begin{array}{c}\text { - terapeuta, defensor, } \\
\text { investigador }\end{array}$ \\
\hline
\end{tabular}

Fonte: Gonçalves (2009, p. 31).

Em jeito de conclusão, não obstante a opção pela escolha de um estilo ou outro, "a supervisão é uma acção multifacetada, faseada, continuada e cíclica" (Alarcão \& Tavares, 2003, p.80), sempre com o intuito de melhorar a qualidade do ensino.

\section{CONCLUSÃO}

Teremos que trabalhar muito mais para assegurarmos a melhoria das aprendizagens dos nossos alunos, melhoria das práticas docentes, no desempenho das escolas, na avaliação das políticas educativas e no seu impacto junto das populações, com mais e melhor supervisão. 
Roldão (2007, p. 45) propõe que o conhecimento profissional docente seja adquirido através de processo de formação que deve ser "epistémico e praxiológico permanente", pois trata-se de um conhecimento com características próprias e em constante construção, desenvolvido "sobre, na e pela reflexão", que implica constante análise e, em consequência desta, poderá gerar novas questões e novos conhecimentos.

Santiago (2012) considera que, para melhorarmos o sistema educativo português, deveríamos, nós profissionais de ensino: melhorar as práticas de avaliação no sistema de ensino; adaptarmo-nos melhor às mudanças, pois utilizamos práticas muito enraizadas; utilizar os resultados da avaliação para melhoria das práticas; dar maior importância à avaliação formativa dos alunos; acabar com a relutância no exercer da autonomia, atribuindo maior importância à organização das escolas; atribuir-se mais tempo para formação de professores e para o trabalho de investigação; promover a dimensão da equidade na avaliação do sistema; aprofundar o papel da formação inicial dos professores; melhorar a partilha de boas práticas.

Reconhecemos o supervisor como aquele que irá desencadear potencialidades e aprendizagens significativas, não podendo deixar de o associar à nova utopia de que nos fala Delors e colaboradores (1996), no Relatório das Nações Unidas:

Devemos cultivar, como utopia orientadora, o propósito de encaminhar o mundo para uma maior compreensão mútua, maior sentido de responsabilidade e maior solidariedade, na aceitação das nossas diferenças espirituais e culturais. A educação, permitindo o acesso de todos ao conhecimento, tem um papel bem concreto a desempenhar no cumprimento desta tarefa universal: ajudar a compreender o mundo e o outro, a fim de que cada um se compreenda melhor a si mesmo" (Delors et al., 1996, p.44).

Segundo Azevedo (2011), "o futuro é uma responsabilidade de hoje, que devemos trabalhar em conjunto, no espaço público, antecipando problemas, promovendo continuamente a responsabilidade social de cada um e de todos, pessoas e instituições" (p. 120).

Desejamos que se mantenha a esperança no futuro, com muita humildade e articulação de esforços, mais e melhores compromissos comuns sociais e culturais, melhor cooperação e responsabilidade, mais confiança, de modo a melhorarmos o sistema educativo, ensinando os professores a ensinar, que é um dos objetivos principais da supervisão pedagógica. 


\section{FONTES E BIBLIOGRAFIA}

Alarcão, I. (2009). Formação e supervisão de professores: uma nova abrangência. Sísifo. Revista de Ciências da Educação, 8, 119-128. Disponível em: http://sisifo.fpce.ul.pt/?r=21\&p=119. Consultado em 8 de março de 2013.

Alarcão, I., \& Roldão, M. (2008). Supervisão. Um contexto de desenvolvimento profissional dos professores. Mangualde: Edições Pedago.

Alarcão, I., \& Roldão, M. (2010). Supervisão. Um contexto de desenvolvimento profissional dos professores $\left(2^{\mathrm{a}}\right.$ edição). Mangualde: Edições Pedago.

Alarcão, I., \& Tavares, J. (1987). Supervisão da prática pedagógica uma perspectiva de desenvolvimento e aprendizagem. Coimbra: Livraria Almedina.

Alarcão, I., \& Tavares, J. (2003). Supervisão da prática pedagógica uma perspectiva de desenvolvimento e aprendizagem ( $2^{\mathrm{a}}$ edição). Coimbra: Livraria Almedina.

Azevedo, J. (2011). Liberdade e Políticas Públicas de Educação. Ensaio sobre um novo compromisso social pela educação. Vila Nova de Gaia: Fundação Manuel Leão.

Delors, J., Al-Mufti, I., Amagi, I., Carneiro, R., Chung, F., Geremek, B., Gorham, W., Kornhauser, A., Manley, M., Quero, M. P., Savané, M., Singh, K., Stavenhagen, R., Suhr, M. W. \& Nanzhao, Z. (1996). Educação, um tesouro a descobrir. Relatório para a UNESCO da Comissão Internacional sobre Educação para o século XXI. Porto: ASA.

Gonçalves, J. A. (2009). Desenvolvimento profissional e carreira docente. Sísifo. Revista de Ciências da Educação, 8, 23-36. Disponível em http://sisifo.fpce.ul.pt/?r=21\&p=119. Consultado em 22 de fevereiro de 2012.

Harris, B. (2002). Paradigmas e Parâmetros da Supervisão em Educação. In J. Oliveira-Formosinho (org.), A Supervisão na Formação de Professores II Da organização à pessoa (pp. 133-223). Porto: Porto Editora.

Oliveira-Formosinho, J. (2002). Em direcção a um modelo ecológico de supervisão de professores. Uma investigação na formação de educadores de infância. In J. Oliveira-Formosinho (org.), $A$ Supervisão na Formação de Professores I. Da sala à escola (pp. 94120). Porto: Porto Editora. 
Roldão, M. (2007). Formação de professores baseada na investigação e na prática reflexiva. Desenvolvimento profissional de professores para a qualidade e para a equidade da Aprendizagem ao longo da Vida (pp. 40-50). Lisboa: Ministério da Educação.

Santiago, P. (2012). A avaliação das aprendizagens na Avaliação da Educação. Lisboa: Conselho Nacional de Educação. Disponível em: http://www.cnedu.pt/index.php?option=com_acymailing\&ctrl=archi ve\&task=view\&mailid=19\&key=42e04614a6964114451b5decbe89 2c33\&subid=122-f133a91079e0e4b5de51558362a9217c\&lang=pt. Consultado a 19 de maio de 2012.

Santos, D. (1977). Obras Completas, volume III. Lisboa: Fundação Calouste Gulbenkian.

Tracy, S. J. (2002). Modelos e abordagens. In J. Oliveira-Formosinho (org.), A Supervisão na Formação de Professores I. Da sala à escola (pp. 19-92). Porto: Porto Editora.

Vieira, F. (1993). Supervisão. Uma Prática Reflexiva de Formação de Professores. Porto: Edições ASA. 